\title{
Child Welfare Policy and Practice
}

\author{
Kathleen Coulborn Faller, Guest Editor \\ University of Michigan
}

The underlying message of the articles in this issue of Children and Youth Services Review is the need for empirically based planning and practice in child welfare services. One of the shortcomings of these services is that they have been driven by "practice wisdom", economic and political expediency, or a selective consideration of the research (Nelson, 1984).

Dramatic changes have occurred in child welfare service delivery during the last 30 years. The "discovery of the battered child syndrome" (young children with multiple inflicted injuries at various stages of healing) by Kempe and his colleagues (1962) signaled a new era in child welfare (Faller, 1981; Kadushin \& Martin, 1988). These researchers, who were pediatricians, radiologists, and psychiatrists, conducted a survey which identified 302 battered children who were seen in 88 hospitals across the country. This work led to heightened concern about children who were being maltreated, and ultimately was instrumental in the passage of federal lcgislation (PL 93-247-Child Abuse Prevention and Treatment Act, 1974) and corresponding state laws, which created and elaborated child protective services (Faller, 1981; Kadushin \& Martin, 1988; Nelson, 1984). Of interest is the fact that an equally important study by David Gil (1970), which documented the association between poverty and minority status and being reported for child abuse, was largely ignored by legislators and others designing child protective services.

The model adopted for child protective services is essentially a crisis intervention model. Its assumption is that child maltreatment is precipitated by a parental or family crisis. The protective services worker is intended to enter the family, while it is in crisis, and provide short-term services, which alleviate the crisis and return the family to its previous, 
presumably adequate level of functioning. This model is more consistent with dynamics leading to physical abuse than neglect or sexual abuse; however, neglect and sexual abuse make up approximately three-fourths of cases referred to protective services (American Association for Protecting Children, 1989). As well, the model does not take into account such environmental factors as chronic poverty and societal values related to sex roles, that are difficult to change.

A central component of child protective services is the reporting requirement, which mandates that professionals working with children report suspected maltreatment to protective services. The reporting requirement, with its accompanying safeguards for reporters and penalties for those who fail to report, has led to impressive increases in the number of referrals, from approximately 650,000 in 1976 (the first year national data were accumulated) to over 2.2 million in 1988 (American Association for Protecting Children, 1989; Daro \& Mitchel, 1989).

As the number of reports has dramatically increased, the resources of protective services have been strained. Protective services has not been able to fulfill its mandate of intensive intervention in families to address the problems that led to child maltreatment. As a consequence, protective services has had to resort to removal of children and their placement in substitute care.

The result has been the revival of foster care. After passage of legislation that set up the Aid to Dependent Children (now Aid to Families with Dependent Children) program in the 1930s, the use of foster care had declined. Previously children had been placed in foster and other substitute care when their parents were without income to support them (Kadushin, 1980).

As maltreated children were removed from their homes by protective services, the number of children in foster care and other placements grew rapidly, so that by 1978 there were 500,000 children in placement (Children's Defense Fund, 1978). Not only is placement quite costly, but it began to be considered potentially detrimental. Once children were removed from unsafe environments, they might be forgotten by their workers, who became preoccupied with the next case crisis. Children not only languished in placement, but were often moved from one placement to another, for a variety of reasons, frequently into progressively more restrictive and costly settings. 
Concerns about the increasing numbers of children in placement and lack of resolution of their situations ${ }^{1}$, either by returning them home or by placing them permanently in alternative living situations, led to new legislation. In 1980, the Congress passed Public Law 96-272, the Adoption Assistance and Child Welfare Act. It was designed to prevent placement when possible, to assure appropriate services to children who were removed from their homes, to facilitate timely resolutions of their situations, and to subsidize their adoptions when necessary.

The passage of PL-96-272 stimulated the development of innovative, intensive family-focused intervention and treatment and gave renewed support to programs that had already been developed. Perhaps the most popular of these is the Homebuilder's Model, described in Spaid and Fraser's article. Although accepting the underlying assumption of the protective services system that families become dysfunctional as a consequence of some crisis that will respond to short-term intervention, the Homebuilders Model nevertheless remedies a fundamental shortcoming of protective services in that it does succeed in providing intensive services.

Coincident with advocacy for prevention of removal of children from their homes came advocacy for prevention of their maltreatment in the first place. Prevention programs are focused on high risk parents and on children, particularly when the concern is sexual abuse. The prevention movement has both inspired and been supported by state level Children's Trust Fund programs. As Poertner, Smith, and Fields point out in this volume, Children's Trust Funds exist in almost every state today. Supported by contributions, state tax check-off provisions, and other resources, they provide modest grants, contingent upon a local funding match, to support primary and secondary prevention programs (Children's Trust Fund for the Prevention of Child Abuse, 1990).

The historical perspective presented here is rather selective, but captures essential features of the current child welfare service delivery system. The system is built upon assumptions that the vast majority of maltreated children will fare better with their families than in other living situations, that social structural problems do not underlie child maltreatment, that short-term intervention with maltreating families is the intervention approach of choice, and that effective prevention of maltreatment can be provided with minimal funding. This model of service delivery has not been systematically evaluated. The articles in this volume speak to this striking shortcoming. All are concerned with the quality of existing services to children and/or their evaluation.

\footnotetext{
${ }^{1}$ Although this concern may originate in a commitment to the welfare of children, it is almost always accompanied by an argument that home-based services and maintaining children in their homes are much cheaper.
} 
Ozawa critically examines trends in AFDC, the program that is supposed to allow children to remain with their single parents. She asserts that the Family Support Act of 1988 has shifted the goal of AFDC from a maintenance program to a transitional program, aimed at preparing mothers for the labor force. She notes a short-sightedness in the Family Support Act, for it fails to provide for an adequate standard of living for the children of these women. The children are an increasingly scare yet vital resource, because they will have to support an aging population.

Three of the articles in this volume address the issue of prevention of child maltreatment. Poertner, Smith, and Fields focus on programs aimed at prevention of physical abuse. Their concern is with quality control, as reflected in program design, implementation, and evaluation. They propose a model of quality control, which derives from a model implemented by Children's Trust Funds in Texas and Kansas.

Richey, Lovell, and Reid focus on mothers at risk for maltreating their children. They present the results of a pilot study to improve the interpersonal skills of these women, the assumption being these skills will decrease their isolation and the consequent propensity to maltreat their children.

Duerr-Berrick's article deals with prevention of sexual abuse and specifically programs geared toward pre-school children. She emphasizes the necessity for a broad range of knowledge when designing programs, for she points out the need to understand cognitive functioning of preschoolers, particularly in the area of moral development, when designing prevention programs for them.

Spaid and Fraser address prevention of placement, rather than of the maltreatment per se in their important study of the use of the Homebuilders Model. The programs they evaluated were in two different geographic areas, which have different cultures, and the models of service delivery are somewhat different. As well, the spectrum of cases that are referred for child welfare services are included in their sample. They are able to identify the types of cases for which intensive, home-based services are more and less likely to prevent placement. An issue which still needs to be addressed by research, and one largely ignored in current child welfare practice and research, is the sufficiency of prevention of placement as an outcome criterion. What is the quality of life for maltreated children who remain with their families (Barth \& Berry, 1987)?

My article attempts to assess the efficacy of the current protective services model for children who have been sexually abused. It raises serious questions about the suitability of crisis intervention and family preservation in situations of child sexual abuse.

Combs-Orme is concerned with service quality for children in foster care. Noting the prevalence of health problems among children in place- 
ment, she catalogues the considerable short-comings of health care for these children.

The studies in this volume represent a preliminary effort at critically examining the current child welfare service delivery system. There is a serious need to evaluate the full range of services that are supposed to protect and nurture children. Policy and practice should be predicated on process and outcome evaluation. The reality of limited and continuously decreasing child welfare funding reinforces the importance of assuring limited resources are wisely spent.

\section{References}

American Association for Protecting Children. (1989). Highlights of official child neglect and abuse reporting, 1987. Denver: American Humane Association.

Barth, R., \& Berry, M. (1987). Outcomes in child welfare services under permanency planning. Social Services Review 61(1):71-90.

Children's Defense Fund. (1978). Children without homes. Washington, D.C.: Children's Defense Fund.

Children's Trust Fund for the Prevention of Child Abuse. (1990). Request for proposals. Lansing, MI.: State of Michigan.

Daro, D., \& Mitchel, L. (1989). Child abuse fatalities continue to rise: Results of the 1988 annual fifty state survey. Chicago: The National Center on Child Abuse Prevention Research.

Faller, K.C. (1981). Social work with abused and neglected children. New York: The Free Press.

Gil, D. (1970). Violence against children. Cambridge: Harvard University Press.

Kadushin, A. (1980). Child welfare services (3rd ed.). New York: MacMillan.

Kadushin, A., \& Martin, J. (1988) Child welfare services (4th ed.). New York: MacMillan.

Kempe, C.H., Silverman, F., Steele, B., Droegmueller, W., \& Silver, H. (1962). The battered-child syndrome. Journal of the American Medical Association. 181: $17-24$.

Nelson, B. (1984). Making an issue of child abuse. Chicago: University of Chicago Press.

Public Law 93-247, The child abuse prevention and treatment act., 1974.

Public Law 96-272, The adoption assistance and child welfare act, 1980. 